3) E. Wertheim : J. Am. Chem. Soc., 48, 826 (1926)

4) Zeise: Ann., 62, 375

Salmon: J. Pr. [2] 8, 115

5) Freund Bachrach: Ann., 285, 201; Braun:Ber., 35, 3380

6) Moore, Crossley; Org. Synth. Coll. volt., 3, 617
7) Thiele: Ann., 302, 249

8) Wheele, Barns: Ann., 22, 146 (1898)

9) Wheele, Merrlam: J. Am. Chem. Soc., 29, 482 (1907)

10) 古川: ゴム協, 33, 969 (昭 35)

\title{
STUDIES ON ORGANIC RUBBER CHEMICALS
}

\section{ACTION OF SECONDARY VULCANIZATION ACGELERATOR ON NATURAL RUBBER}

R. Yamamoto, J. Furukawa, K. Matsuura, \& S. Yamashita (Department of Synthetic Chemistry, Kyoto University)

We have found that the reagents of structures of $\mathrm{CH}_{3}-\mathrm{X}-\mathrm{C}-\mathrm{ZH}$, in which $\mathrm{X}, \mathrm{Y}$ and $\mathrm{Z}$ indicated

hetero-atoms other than carbon in promoted vulcanization of natural rubber in the presence of dibenzothiazyldisulfide (DM). Such a reagent was named secondary vulcanization accelerator. The reagents used in the present paper were thiophenol, thioacetic acid, dithioacetic acid, trithiocarbonate, thioacetoamide, methylxanthogenimide, methyldithiocarbamate, monomethylthiourea, aniline, acetoamide, urethane, S-methylmonocarbamate, monomethylurea, hydrochloride salt of acetoamidine, and hydroiodide salt of pseude-0-methylthiourea. It was shown that all of these reagents promoted DM and that some of these reagents, i. e., thioacetic acid, thioacetoamide and methylthiourea, were able to perform non-sulfur vulcanization of natural rubber in the presence of DM. It illustrated also that non-sulfur vulcanization at low temperature was posible by use of such curing system.

\section{二次加硫促進作用および無硫黄架橋作用}

(昭和37年1月12日 受理)

$$
\begin{array}{lll}
\text { 山本 隆 } \text { 造* 古 川 淳 二* }^{*} \text { 松 浦 }- \text { 雄 }^{*} \text { 山下 晋 三* }
\end{array}
$$

\begin{abstract}
要 旨 加硫促進郕ジンンソチアジシサルファイトと一般棈造式 $\mathrm{CH}_{\mathrm{a}}-\mathrm{X}-\mathrm{C}(=\mathrm{Y})-\mathrm{ZH}$ 型の含異節元

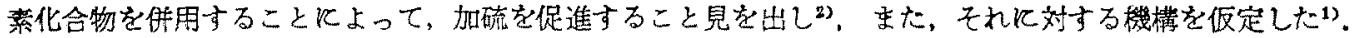

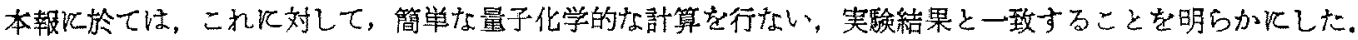
また無硫黄架橋の場合も，同じ機構で反忍が行なわれていることを仮定した。
\end{abstract}

\section{1. ま $え$ がき}

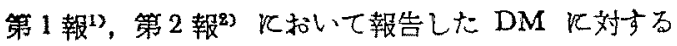
二次加硫促進作用扰よび DMの無硫黄架橋反心の機構在 つぎの如く解䣋する。まず二次加硫促進作用において。 二次加硫促進剂が，何等かの形でDMを攻撃し,DMをう

†本報を[有機ゴ么薬剂の研觉（第 3 報)]とする.

* 京都大学工学部合成化学教室
シカル解離させる．その程度け弱いので，単独でそのう シカルがム分子から水素引拔居応を起こすに至らな いで，多量に存在する硫黄を攻慗してS かくして開環した硫鱼は通常の加硫反応に從ってゴム分 子火梧かけを行な5かけである。い亡二次加硫促進剂と して非常飞強力な化合物か，DMと併用された場合を考

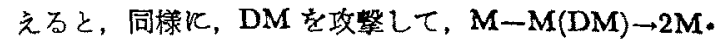
と逰離ラシカルが生成するため、これは，コム分子から 
水素を引抜き， $\mathrm{M}-\mathrm{H}(\mathrm{M})$ となるである5。（実際飞 は， $\mathrm{ZnO}$ の存在下で加硫反応が進むため，M-Zn-M がその最終的形体であると考えられる)。

同㯲なシサルフフイド加硫促進剂がアミンルより活性 化される機構火関しては，2,3 研究がされており，例 克は， B.A.Dogadkin らはつきの如く報している32.

$$
R S S R+R^{\prime} R^{\prime \prime} N H \longrightarrow\left[\begin{array}{c}
R S S R \\
R^{\prime} R^{\prime \prime N H}
\end{array}\right]
$$$$
\longrightarrow \mathrm{RSH}+\mathrm{RS} \cdot+\mathrm{R}^{\prime} \mathrm{R}^{\prime \prime} \mathrm{N} \text {. }
$$

まさ Watson らは，チオウレアとジルファイド 関してつぎの如く報じているい．

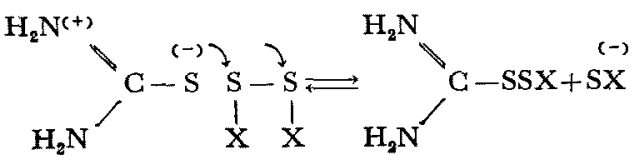

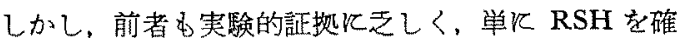
認しているにすきず，実験の種類む少数である。さらに Watson らの説は，全く単なる推測飞すぎい。

本研究では,シサルファイドーアミン反応は, Dogadkin らと同様な遊離ラシカルの反応であると考党てお り，彼らの報文ではあいまい忙なっている $\left[\begin{array}{l}\mathrm{R}-\mathrm{SS}-\mathrm{R} \\ \mathrm{R} \mathrm{R}^{\prime \prime} \mathrm{NH}\end{array}\right]$ 型のコンプレックスをさらに定臽的かり，理論的に取扱 ったるのである。

筆者らの考光はつきの通りである。すなわら，二次加 硫促進剂 $\mathrm{CH}_{2}-\mathrm{X}-\mathrm{C}(=\mathrm{Y})-\mathrm{ZH}$ が先ず $\mathrm{DM}$ 陑配位 する。

$$
\frac{\mathrm{H}}{\mathrm{HZ}-\stackrel{\mathrm{C}}{\mathrm{C}}-\mathrm{X}-\mathrm{CH}_{3}}
$$

つき $\mathrm{S}$ と $\mathrm{Y}$ ～と ZH との間極く弱い結合を生 ヒるとともに，一S-S一の切断か起り，つきの如く游 離うジルを生成する.

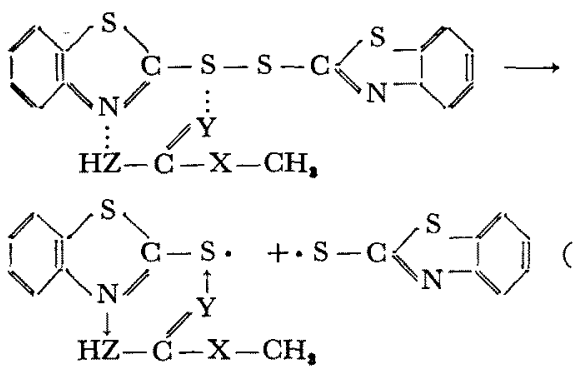

(A)

(B)

かくして生成したラジル(B)はコム分子から水素を引き 抜さ $\mathrm{M}-\mathrm{H}$ となりさらKラシカル我錯化合物が分解し最 終的にはM-H（2メルカプトヘンソチアソール）か生
成する。

結局，この際の錯化合物の安定化の度合，才なわら弱 い結合により生成する錯化合物の安定化の大きな試薬が 無硫黄架橋を行ない得るし，また二次加硫促進剂として も有力で，かつ，反応生成物たる $\mathrm{M}-\mathrm{H}$ の収量も多いか けである.一方，錯化合物の安定化が瑟く，シサルフフ イド結合の切断を起しにくいるのは, 無硫黄架橋を行な い得ず㧘なる二次加硫促進作用学呈するに過ぎない。

\section{DM 亡二次加硫促進剂の反応}

実際の反态は，亚鉛華、ステアリン酸などと併用して ヨ゙ム中で起るものであるが，コム中の反応は非常に解析 が困難なためモデル的につぎの反応を試みた。

チオアセトアミトが，DMと併用して無硫黄架橋する ことおよびアセトアミドが，単なる二次加硫促進作用し か有していないこと2な考甞して，この二者の相違を检 討するため，つぎの二つの反応を試みた。

古市方至

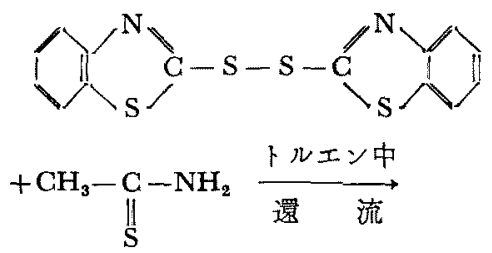

上式の反応(A)で娃溶媒として蒸溜トルエン（狒点1090 G）を用い三ッロフラスコで DM15g とキォアセトアミ F $6 \mathrm{~g}$ を加光，摜汼しなから約 2 時間還流する。店後 系を放置すると黄色針状結晶が析出した。

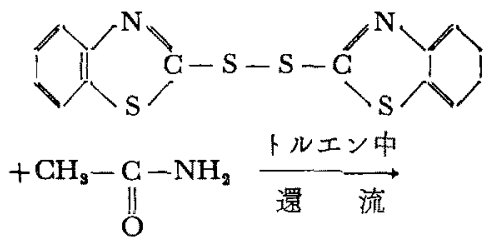

反応(B)に扎しても(A)と同栐にトルエンを溶媒として。 DM15g とアセトアミト $4 \mathrm{~g} と$ と時間還流した。 反応物の分析は表 I括よび表 2，䏡示した通りであっ to.

上の 2 つ反応(A)(B)から明らかとなったよ5飞無硫黄

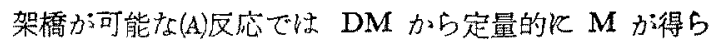

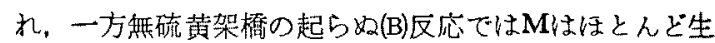
成しない。

この電実加ら無硫黄架橋に際して

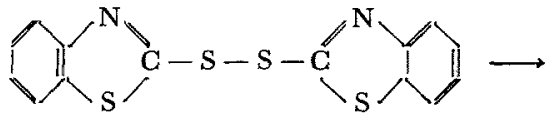


2<smiles>SC1NC2=C(CCC2)S1</smiles>

なる解離が起っていると洘えられる。

表1飞於て〔]は蝠点を示寸。（）炇収量 $\mathrm{g}$ を示 †.

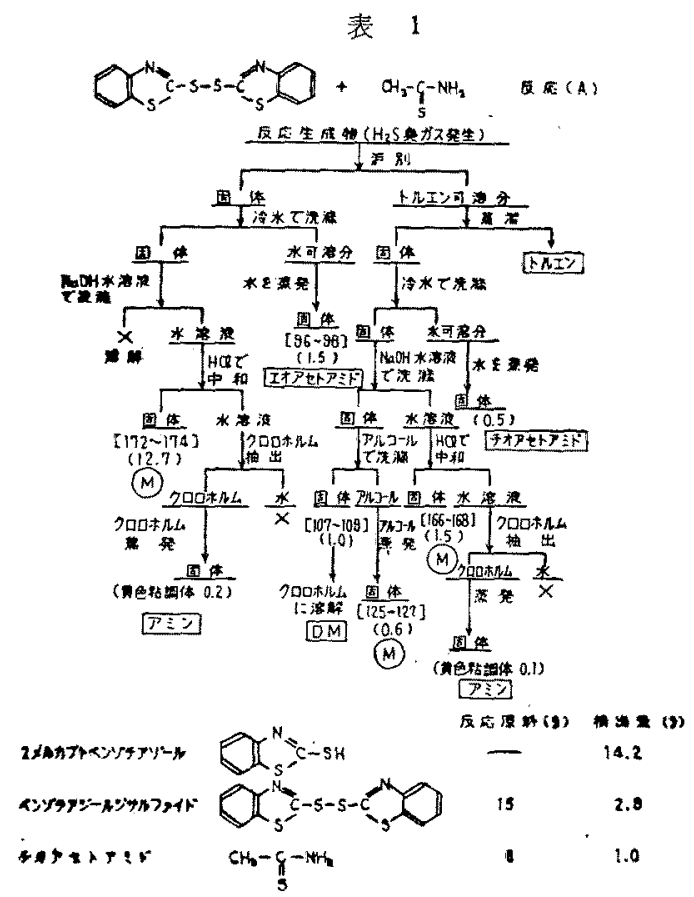

表 2 表1飞漅等

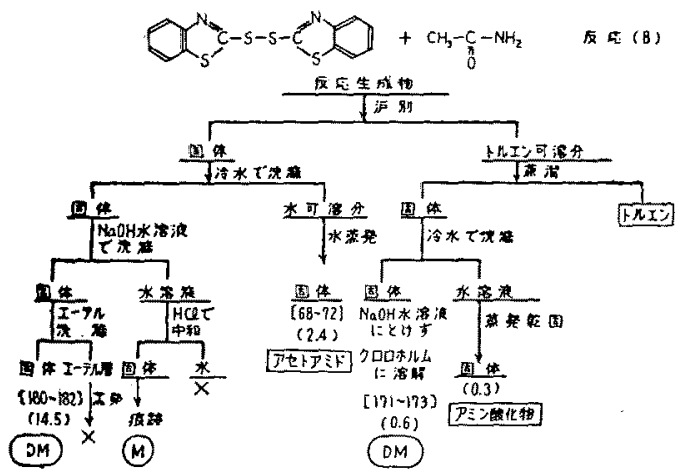

(OM) $\times$ (M)

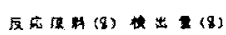

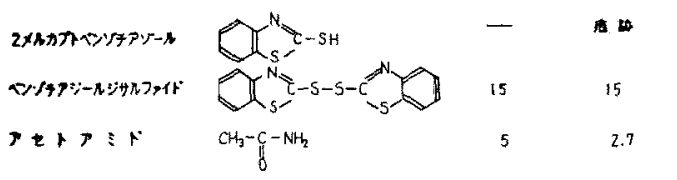

(49)
なお，硫黄架橋か可能なる他の例，ナなからタチル キォウレアにつてを同様な実験をおここなったが，やは りは经洼定量的飞得られ。この際にはM以外飞相当量の

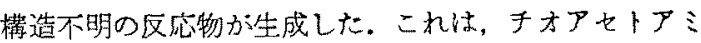
ドの場合にも恐らく生成するはずのアミン系化合物であ ろらが，非常に不安定なため反応中に分解したあのと推 发される。メキルキオウレアの場合には，それか安定で 存在し得たと考えられる。

これに対するさらに詳綀な検討が必要である。

\section{D M 以外のジサルファイドと二次加硫促進 靔で加硫}

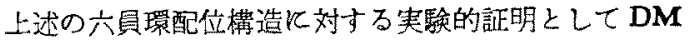
の代りスつきの如き化合物を代用することによって然硫 黄架橋を試みた。

(1)

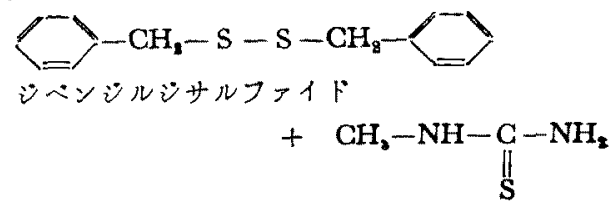

モノタキルチォウレフ

(2)

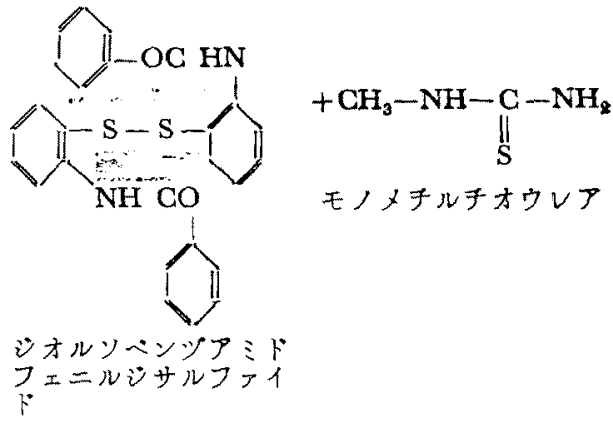

これら2 つの系(1)(2)はいずれる加硫せず六買䍗配位の 重要性か浾された。

すなわら単なるシサルファイドへフミンの不対電子が 攻慗すると云う Watson一派の機栱を支持するならばこ れらの化合物でも，当然無硫黄架橋が起る筈でかる. 従 って DM と二次加硫促進剂との相互作用が，先に示し た六員環配位を取っていることは焉確実と考えられ z.

\section{4. 反応機構の量于化学的取扱い}

第1報》飞扣いて示した如く，反応の第一段階はDM と第 2 報飞执いてて夷駼した如き，二次加硫促進剂との相 互作用に始采る。

いま量子化学的取报いな簡単にするため $\mathrm{R}$ 一 X一の 
えいきよろは単なる誘起効果 (inductive effect) とすき ナ゙反応の本質は $-\mathrm{C}(=\mathrm{Y})-\mathrm{SH}$, およびーC (=Y)$\mathrm{NH}_{2}$ の構造炕より大きく支配されると考える。すなわ

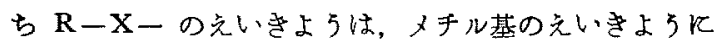
梳一し $\delta_{\mathrm{c}}{ }^{\prime}=-0.2$ を考磨することにし(') $-\mathrm{C}(=\mathrm{Y})$ 一 ZH の分子軌道を計算した。計算飞用いたバラメーター は表 3 の通りである.

\begin{tabular}{crcc} 
& 表 & \multicolumn{3}{c}{3} \\
\hline$-\mathrm{N}=$ & $\delta_{x}$ & $\delta_{c}^{\prime}$ & $\rho_{c x}$ \\
\hline $\mathrm{N}-$ & 1 & 0.1 & - \\
$\mathrm{O}=$ & 2 & 0.2 & - \\
$-\mathrm{O}-$ & 2 & 0.2 & - \\
$\mathrm{C}=\mathrm{O}$ & 3.2 & 0.32 & - \\
$-\mathrm{S}-$ & - & - & 1.4 \\
$-\mathrm{NH}-$ & 1 & 0.1 & - \\
$\mathrm{S}=$ & 2 & 0.2 & - \\
$\mathrm{CH}_{\mathrm{s}}-$ & 0.5 & 0.05 & - \\
\hline
\end{tabular}

これらのパラメーターを用い $\varepsilon=\alpha+\lambda \beta$ として 永年 方程式を解委入を求めた。

表 4 氏 $-\mathrm{C}(=\mathrm{Y})-\mathrm{ZH}$ の分子軌道拉上び各原子の 電子分布を表示寸る。

各原子の順序は次の如くである.

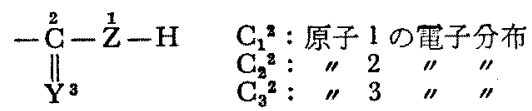

またこの系は 3 轨道 $4 \pi$ 電子系であるため めの大 い值はど下の勃道となり四示するとつぎのようになる。

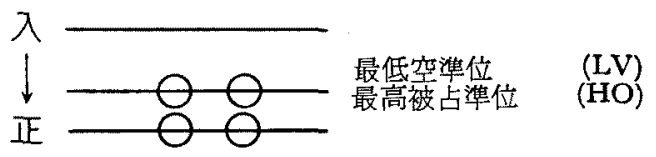

表4亿括いて化合物(1)，(5)，(9)は $-\mathrm{G}(=\mathrm{Y})-$ な $\mathrm{Y}$ る構造であるため互変異性は考文られず唯一つの構造し か取り得ないか，その他の化合物飞つてては，(2)↔(4)， (3)↔(7)，(6)↔(8)，いずれる互変簧性体である。

一方これと相互反店を起す DM を取扱いを簡単にす るためつざの如き単純なモデルを考える。

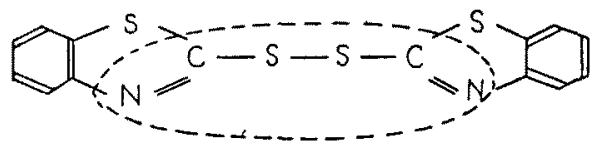

下に示した籁囲の構造のみを取り上げ他のえいきよう は無視して考光る。そ5すると六軌道 $8 \pi$ 電子の分子轨 道となる。パラメーターはつぎの如くした。

$$
\begin{aligned}
& \text { 原子番号 } \stackrel{(1)}{\mathrm{N}}=\stackrel{(2)}{\mathrm{C}}-\stackrel{(3)}{\mathrm{S}}-\stackrel{(3)^{\prime}}{\mathrm{S}}-\stackrel{(2)}{\mathrm{C}}=\stackrel{(1)}{=} \\
& \text { ハランータ } \left.\left.\left.1\right|^{0.2}\right|_{1} ^{1}\right\rceil_{0.2}^{1}
\end{aligned}
$$

分子構造の対称性を考虑して，永年方程式を解いて表 5 K示した分子轨道か得られる。

以上で

$$
\frac{1}{\mathrm{~N}}-\stackrel{2}{\mathrm{C}}-\stackrel{3}{\mathrm{C}}-\mathrm{S}
$$

（I）(II）の全轨道が求まったわけで，これらを用いて 摄動法火上り，（I）（II）の相互反忘を考学る。

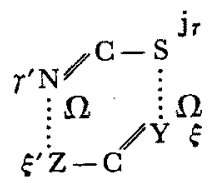

$\gamma$ 位置の原子と $\xi$ 位置の原子の間極く弱い結合か生 していると仮定し，その共鳴積分を几としこれは一定と さる.

桡造( I )の分子の $\gamma$ 一位原子の電子分布を $C_{\gamma}^{j^{*}}$ とし

構造( II)の －位原子の電子分布を $d_{\xi}^{k^{2}}$ とし(I)(I)

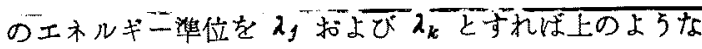
結合を生したための安定化エホルギーはつきの如くな る.

$$
\begin{aligned}
& (\delta \varepsilon)_{r \xi}=2 \sum_{j}^{o c c}\left(\delta \lambda_{j}\right)_{T^{\xi}}+2 \sum_{k}^{\mathrm{occ}}\left(\delta \lambda_{k}\right)_{\gamma^{\prime}}+2 \sum_{j}^{\mathrm{occ}}\left(\delta \lambda_{j}\right)_{\gamma^{\prime} \xi^{\prime}} \\
& +2 \sum_{k}^{\mathrm{occ}}\left(\delta \lambda_{k}\right)_{\gamma^{\prime} \xi^{\prime}} \\
& =2\left(\sum_{j}^{\text {occ unoce }} \sum_{k}^{\text {unoce occ }}-\sum_{j} \sum_{k}\right) \frac{C_{j}^{j^{2}} \cdot d_{\xi}^{k^{2}}}{\lambda_{j}-\lambda_{k}}(\tau)^{2}+2 \sum_{j}^{\text {occ }}
\end{aligned}
$$

$\{(\delta \lambda j)$ の 4 次の項 $\}$ $+2 \underset{k}{o c c}\left\{\left(\delta \lambda_{k}\right) の 2\right.$ 次の項 $\}$ 
表 4

分子韩畺と電子密度分布

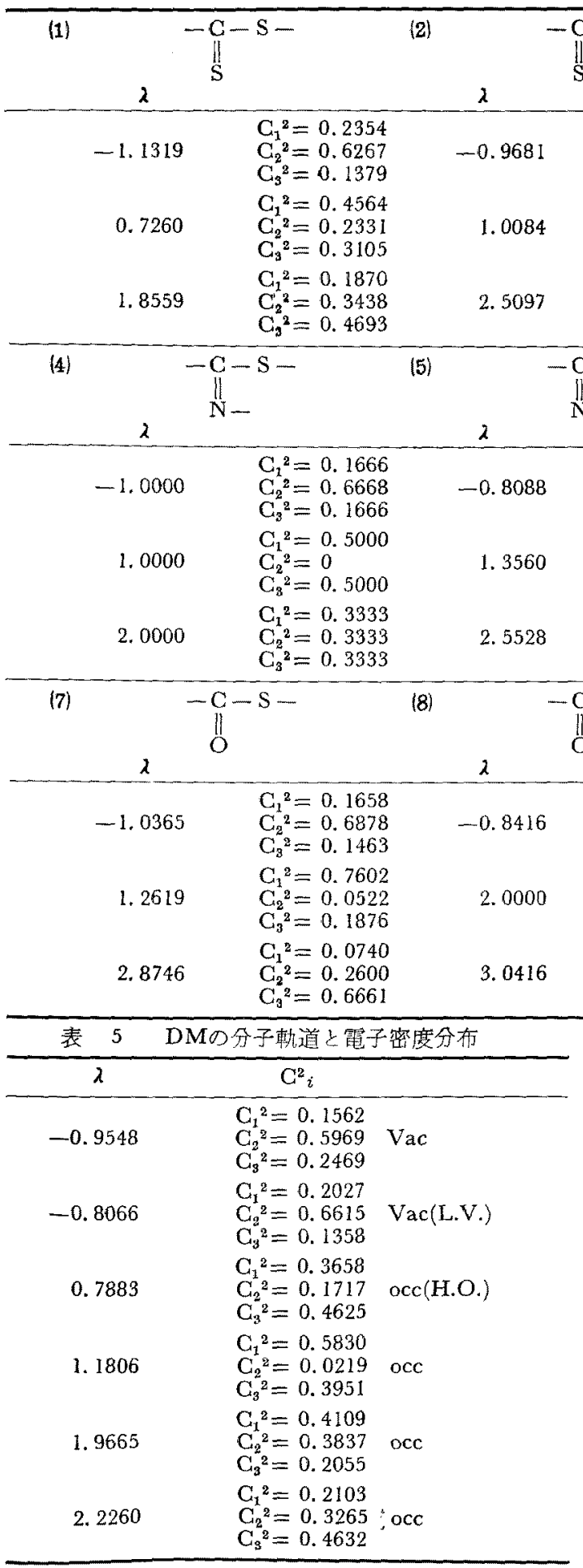

(3)<smiles>Cn1ccn1C</smiles>

$\lambda$

$\mathrm{C}_{1}{ }^{2}=0.0720$
$\mathrm{C}_{2}{ }^{2}=0.6339$
$\mathrm{C}_{3}{ }^{2}=0.2941$
$\mathrm{C}_{1}{ }^{2}=0.1728$
$\mathrm{C}_{2}{ }^{2}=0.1699$
$\mathrm{C}_{3}{ }^{2}=0.6573$
$\mathrm{C}_{1}{ }^{2}=0.7552$
$\mathrm{C}_{2}{ }^{2}=0.1962$
$\mathrm{C}_{3}{ }^{2}=0.0486$

$-\mathrm{C}-\mathrm{O}-$

$-0.8300$

$\mathrm{C}_{1}^{2}=0.0378$

$\mathrm{C}_{2}{ }^{2}=0.0147$

$\mathrm{C}_{3}{ }^{2}=0.3475$

$\mathrm{G}_{1}^{2}=0.0699$

$1.1700 \quad \mathrm{C}_{2}^{2}=0.2881$

$\mathrm{C}_{\mathrm{a}}{ }^{2}=0.6419$

$\mathrm{C}_{1}{ }^{2}=0.8923$

$\mathrm{C}_{2}^{2}=0.0972$

$\mathrm{C}_{3}{ }^{2}=0.0106$

3.5300
$\mathrm{C}-\mathrm{N}<$

$-\mathrm{O}-$

- $\|_{\mathrm{N}}-\mathrm{O}-$

$\lambda$

$\begin{array}{lll}\mathrm{C}_{1}{ }^{2}=0.0885 & & \mathrm{C}_{1}{ }^{2}=0.0470 \\ \mathrm{C}_{2}{ }^{2}=0.6981 & -0.6471 & \mathrm{C}_{2}{ }^{2}=0.6963 \\ \mathrm{C}_{3}{ }^{2}=0.2133 & & \mathrm{C}_{3}{ }^{2}=0.2567 \\ \mathrm{C}_{1}{ }^{2}=0.2133 & & \mathrm{C}_{1}{ }^{2}=0.0717 \\ \mathrm{C}_{2}{ }^{2}=0.0885 & 1.5256 & \mathrm{C}_{2}{ }^{2}=0.2009 \\ \mathrm{C}_{3}{ }^{2}=0.6982 & & \mathrm{C}_{3}{ }^{2}=0.7274 \\ \mathrm{C}_{1}{ }^{2}=0.6982 & & \mathrm{C}_{1}{ }^{2}=0.8813 \\ \mathrm{C}_{2}{ }^{2}=0.2134 & 3.5415 & \mathrm{C}_{2}{ }^{2}=0.1028 \\ \mathrm{C}_{3}{ }^{2}=0.0885 & & \mathrm{C}_{3}=0.0159\end{array}$

$\begin{array}{lll}\mathrm{C}-\mathrm{N}< & (9) & -\mathrm{C}-\mathrm{O}- \\ & & \end{array}$

$\lambda$

$\mathrm{C}_{1}^{2}=0.0906$

$\mathrm{C}_{2}{ }^{2}=0.7318$

$\mathrm{C}_{3}{ }^{2}=0.1776$

$-0.6718$

$\mathrm{C}_{1}{ }^{2}=0.0491$

$\mathrm{C}_{\mathrm{x}}{ }^{2}=0.6622$

$\mathrm{C}_{2}{ }^{2}=0$

$\mathrm{C}_{3}{ }^{2}=0.3378$

5296

$\mathrm{C}_{2}=0.7456$
$\mathrm{C}_{3}=0.2048$

$\mathrm{C}_{3}{ }^{2}=0.2472$

$\mathrm{C}_{2}{ }^{2}=0.2682$

$\mathrm{C}_{3}{ }^{2}=0.4846$

2. 5296

$\mathrm{C}_{1}{ }^{2}=0.2176$

$\mathrm{C}_{2}^{2}=0.0979$

$\mathrm{C}_{3}{ }^{2}=0.6842$

3. 6622

$\mathrm{C}_{1}{ }^{2}=0.7325$

$\mathrm{C}_{2}{ }^{3}=0.1565$

$\mathrm{C}_{3}{ }^{2}=0.1110$

$$
+2\left(\sum_{j}^{\text {occ unocc }} \sum_{k}^{\text {unocc occ }}-\sum_{j} \sum_{k}\right) \frac{C_{\gamma^{\prime}}^{j^{\prime} \cdot} \cdot d_{\xi^{\prime}}^{k^{3}}}{\lambda_{j}-\lambda_{k}}(r)^{2}+2 \sum_{j}^{\text {occ }} \text {. }
$$

$\left\{\left(\delta \lambda_{j}\right)\right.$ の 4 次の項 $\}$

$$
+2 \sum_{k}^{o c c}\left\{\left(\delta \lambda_{k}\right) の 4 \text { 次の項 }\right\}
$$

したがって，4次以上の項高無視すればつぎの量を垶 算すれば充分で市。

$$
\Delta E\left(\sum_{j}^{\text {occ unoce }} \sum_{k}^{\text {unoce oce }}-\sum_{j} \sum_{k}\right) \frac{C_{r}^{j^{2}} \cdot d_{\xi}^{k^{2}}+C \cdot d_{r^{j}}^{j^{2}} \cdot d_{\xi}^{k^{2}}}{\lambda_{j}-\lambda_{k}}
$$

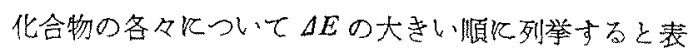
6 の如くなる。 
表 6

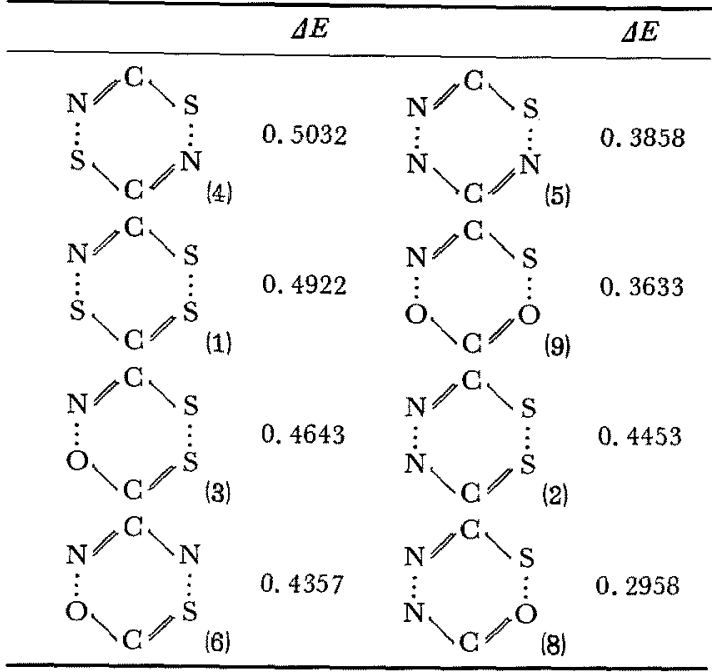

表 6 より(1)支除けば二次加硫促進能と $\Delta E$ の大ささは

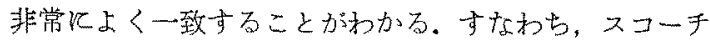
試䮖の祭に測定された $\Delta t_{5}$ 叔よびブランク試験の $\Delta t_{0}$ と の差 $\left(\Delta t_{0}-\Delta t_{5}\right)$ 恪各二次加硫促進剂の二次促進反応の 相刘的速度恒数に相当する量であり，この対数 $\log \left(\Delta t_{0}\right.$ 一 $\left.\Delta t_{5}\right)$ を横軸に $\Delta E$ を縦軸にとって双ると良く直線関 係が得られる。

図1Kこの関係を示す。

- $\mathrm{C}(=\mathrm{S})-\mathrm{S}$-飞関しては，先才゙溶解度の問題吕考 えられ，さらに全く異った反岕，ゴムに対するアダクト の可能性が挙げられる.また，メカニズムの全く別の道 老とっていること加予想さ机，これらに関してはさられ 詩細な検討老要する。

を大表6中の(2)出よび(8)より明らかな如く，アミンの

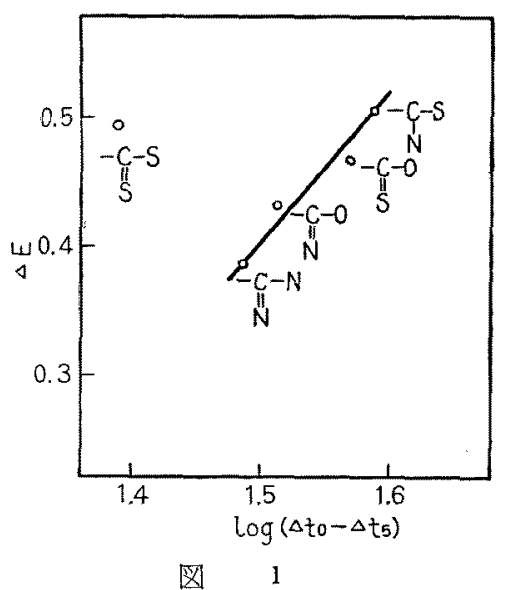

$\mathrm{NH}_{2}$ は必らず= $\mathrm{NH}$ の型を取って反応する。すなわち $\mathrm{H}_{2} \mathrm{~N}-\stackrel{\mathrm{C}}{\mathrm{C}}=\mathrm{Z}$ の型取ると $\Delta E$ 世 $\mathrm{HN}=\stackrel{\mathrm{C}}{\mathrm{C}}-\mathrm{ZH}$ の場合 に比して減少する。

以上の䒠験的考察および理論的荐祭により明白な如 く，DM 二次加硫促進反応と DM の無硫黄架橋反応 とは，本筫的炕は，同一の反応で方り，六員環を形成し た錯塩型で進行すると考觉るのが妥当である。

文 献

1)山本，古川，新田，山下：ゴム協, 35, 12 (1962)

2）山本，古川，松浦，山下：ゴ協，35，322(1962)

3) B.A.Dogadkin, M.S.Feldshtein: R.C.T., 254 (1959)

4) Watson; J. of Appl. Poly. Sci., 3, 371 (1960)

5) 東, 馬場「量子有機化学」（1955）

6) B. Pullman, A.Pullman : Rev. Mod. Phys.s 32 $428(1960)$

\section{STUDY ON ORGANIC RUBBER GHEMICALS}

\section{THE ACTION OF SECONDARY VULGANIZATION ACCELERATOR AND NON-SULFUR VULCANIZATION BY DIBENZOTHIAZYL DISULFIDE,}

R. Yamamoto, J. Furukawa, K. Matsuura, \& S. Yamashita (Department of Synthetic Chemistry, Kyoto University)

In the previous paper we had shown that the reagent of the structure of $\mathrm{CH}_{3}-\mathrm{X}-\mathrm{G}-\mathrm{ZH}$ had effect

of secondary vulcanization accelerator to rubber in the presence of dibenzothiazyl disulfide (DM) and we suggested a mechanism of acceleration by using quantum chemical calculation.

As the results, the scorch time, $\Delta \mathrm{t}$, of rubber ingrediated with the secondary vulcanization accelerator was shown to correlate linearly with its resonance stability, $\Delta \mathrm{E}$.

It is proposed that the reaction takes place DM and secondary vulcanization accelerator to form sixmembered ring complex and in the case of non-sulfur vulcanization its radical abstracts hydrogen followed by to dissociate into unstable radicals. And in the absence of sulfur the radical from accelerator abstracts hydrogen atom from rubber molecule and in the presence of sulfur it may attack sulfur ring to form sulfur radicals and cross-linking of rubber may be brought about. 